\title{
Textural properties in density-separated coal fractions
}

Fernando Rubiera ${ }^{\mathrm{a}}$, José B. Parra ${ }^{\mathrm{a}}$, Ana Arenillas ${ }^{\mathrm{a}}$, Steve T. Hall ${ }^{\mathrm{b}}$, Chandu L. Shah ${ }^{\mathrm{b}}$ and José J. Pis ${ }^{\mathrm{a}}$

anstituto Nacional del Carbón, CSIC, Apartado 73, 33080, Oviedo, Spain

${ }^{\mathrm{b}}$ School of Chemical, Environmental and Mining Engineering, University of Nottingham, NG7 2RD, United Kingdom

\begin{abstract}
The results presented in this work are part of a more extensive research program aimed at assessing the impact of coal porous structure on density-based process evaluation and modelling. The coal samples used were obtained from two different density-based cleaning processes, a Vorsyl dense medium separator for treating an anthracite (TW) with a size fraction of $0.5-8.0 \mathrm{~mm}$ and a spiral concentrator for treating a bituminous coal $(\mathrm{DH})$ with a size of less than $2 \mathrm{~mm}$. Textural characterisation of the samples was carried out by measuring true (helium) and apparent (mercury) densities and mercury porosimetry up to a maximum pressure of $200 \mathrm{MPa}$. Adsorption isotherms in $\mathrm{CO}_{2}$ at $273 \mathrm{~K}$ were also determined for both coal series. In the case of the bituminous coal series a linear relationship between porosity and ash content was found. This may have important implications if coal porosity and/or textural parameters need to be incorporated into new density-based simulation models.
\end{abstract}

Keywords: Coal; Density separation; Textural characterisation

\section{INTRODUCTION}

Practically all aspects of coal utilisation are influenced by porosity and pore structure; for instance, gasification, liquefaction, production of metallurgical coke and activated carbon ${ }^{1}$. Similarly coal beneficiation can also be affected by the porosity of coals. It has been reported by researchers that coal porosity may have a significant effect on dewatering ${ }^{2}$ and froth flotation of coal $^{3}$. The latter paper also showed that adding reagents to coal in a fixed proportion to the coal mass without any knowledge of the internal pore structure may give misleading results. Coal float-sink separation, on the other hand, is commonly performed down to about $0.5 \mathrm{~mm}$ particle size in order to 
predict washability as a function of top size and size distribution. This helps, among other factors, in the design of coal preparation plant flowsheets and to monitor the performance of preparation equipment ${ }^{4}$. Current performance prediction models of density-based coal separation processes are based on historic data derived from floatsink testing using organic liquids. The reliability of such data is now being questioned in the light of the effects of using dried feed coal samples and the influence of coal porosity. This in turn, may have important implications for determining the washability characteristics of the coal (i.e. washability data) and for determining coalwashery performance with partition curves and computer plant simulation models. In fact, models generated using float-sink data from a narrow range of coal samples give simulation results that sometimes poorly fit the real plant data, and this has also been attibuted to coal porosity ${ }^{5}$. Anomalies have been observed to occur when treating the results of conventional float-sink testing and similar anomalies have also occurred during the construction of partition curves. These effects have been attributed to the porous structure of coal. Because of this pore structure must be considered before an analysis of this type is undertaken ${ }^{6,7}$. Since float-sink analysis is the cornerstone in the development of density-based simulation models, the effects of coal porosity must be quantified before being incorporated into new models.

The present work is part of a more general study into the separation performance of various coal cleaning processes and into the effect of coal porous structure on densitybased process evaluation and modelling. Textural characterisation of a number of coal samples obtained from two different coal cleaning devices was carried out. The main objective of the work was to determine the variation of coal textural properties in several coal samples (clean coal, middling and reject) and relative density fractions.

\section{EXPERIMENTAL}

The two samples of coals used in this study were an anthracite (TW) and a bituminous coal (DH) from the U.K. The anthracite sample was obtained from a Bretby Vorsyl dense medium fine coal cleaning process using 0.5-8.0 mm sized coal. Samples of raw feed, clean coal and the reject were collected and sized down to 4, 2, 1 and 0.5 $\mathrm{mm}$. The sized samples were further float and sink separated, using sodium polytungstate (SPT) inorganic medium, at 1.4, 1.5, 1.6, 1.7, 1.8, 2.0 and 2.2 relative 
densities (RD). The bituminous coal samples were the products of a separation of minus $2 \mathrm{~mm}$ size in a spiral separator. Collected clean coal, middlings and the reject samples were sized down to $1,0.5$ and $0.25 \mathrm{~mm}$. The samples were all dried at $105^{\circ} \mathrm{C}$ prior to ash determination and further analysis.

Textural characterisation of the coal samples involved determination of true and apparent densities by $\mathrm{He}$ and $\mathrm{Hg}$ displacement, respectively, and mercury porosimetry. The total surface areas of the samples were determined from $\mathrm{CO}_{2}$ adsorption isotherms at $0^{\circ} \mathrm{C}$. True density was measured by using an AccuPyc 1330 pycnometer. This apparatus determines sample volume by measuring the pressure change of a probe gas in a calibrated volume ${ }^{8}$. Helium was used as probe gas because it is the smallest atom available. Therefore, it has the best chance of penetrating almost all pores in coal (excluding closed porosity). A Carlo Erba Macropore Unit 120 was used to determine apparent density with mercury at $0.1 \mathrm{MPa}$. From true and apparent densities the open porosity can be calculated as:

$\varepsilon=\left(1-\frac{\rho_{H g}}{\rho_{H e}}\right) 100$

where $\varepsilon$ is the open porosity (\%), and $\rho_{\mathrm{Hg}}$ and $\rho_{\mathrm{He}}$ are apparent and true densities $\left(\mathrm{g} \mathrm{cm}^{-3}\right)$ determined in $\mathrm{Hg}$ and $\mathrm{He}$, respectively. Similarly, the total pore volume, $V_{T}$, can be obtained from the equation:

$V_{T}=\left(\frac{1}{\rho_{\mathrm{Hg}}}-\frac{1}{\rho_{\mathrm{He}}}\right)$

Pore volume distributions were evaluated with a mercury porosimeter Carlo Erba 2000 , which provides a maximum operating pressure of $200 \mathrm{MPa}$.

The adsorption isotherms of $\mathrm{CO}_{2}$ at $0^{\circ} \mathrm{C}$ were determined in a Gemini III 2375 surface area analyser. Preparation of the samples involved drying approximately $5 \mathrm{~g}$ sample at $130^{\circ} \mathrm{C}$ for 24 hours under vacuum. The Dubinin-Radushkevich (DR) equation ${ }^{9}$ was used to derive micropore volumes: 


$$
W=W_{0} \exp \left\{-1\left[\left(1 / \beta E_{0}\right) R T \ln \left(p^{0} / p\right)\right]^{2}\right\}
$$

where $W$ is the volume of adsorbate within the pore structure at relative pressure $p / p^{0}$ ( $p$ being the equilibrium and $p^{0}$ the saturation vapour pressures at the adsorption temperature $T) . W_{0}$ is the micropore volume of the adsorbent, $E_{0}$ is the characteristic adsorption energy which is related to the accessibility of the micropore system, $\beta$ is the affinity coefficient, which describes the adsorbability of the adsorptive, with a value of 0.47 for $\mathrm{CO}_{2}$. The total surface area $\left(\mathrm{S}_{\mathrm{DR}}\right)$ was obtained by multiplying $W_{0}$ by the cross-sectional area of the $\mathrm{CO}_{2}$ molecule ${ }^{10}\left(0.187 \mathrm{~nm}^{2}\right)$.

The average micropore width, $L$, was calculated from the expression proposed by Stoeckli and Ballerini ${ }^{11}$ :

$L=10.8 /\left(E_{0}-11.4\right)$

Following this assumption the area of slit-shaped micropores $\left(S_{m i}\right)$ was obtained by the following expression:

$$
S_{m i}=2 \times 10^{3} W_{0} / L
$$

\section{RESULTS AND DISCUSSION}

\section{Densities and porosity}

Tables 1 and 2 show the true and apparent densities as well as porosities and total pore volume of the TW and DH coal samples, respectively, obtained from equations 1 and 2. In addition, all results were expressed on a mineral-matter containing basis. In the case of the TW coal series there was, as could be expected, an increase in both densities with the relative density of separation, i.e. with the ash content. A similar behaviour was obtained for the apparent density. All the TW coal samples presented low porosities, the values being below 5\% open porosity. This is in agreement with the rank of the coal, an anthracite. It has been found that anthracites have low 
porosities while low volatile bituminous coals have even lower porosities, porosity increasing for lower rank coals ${ }^{7}$.

The DH coal series displayed higher porosities and total pore volumes, as can be seen in Table 2. Porosity values in the order of $15-17 \%$ were obtained for the clean coal fractions. The reject of 1-2 mm size fraction with the highest ash content, $77.6 \%$, presented the lowest porosity value, $6.77 \%$. A linear relationship was found between the porosity and ash content of the DH coal samples, as can be observed in Figure 1. Clear differences in the textural parameters of this coal series were obtained in contrast with the results displayed by the TW coal samples. The latter effect was partially due to the low porosity values of the TW series, which made the porosity differences between the different fractions more difficult to appreciate.

Mercury porosimetry was also carried out up to a maximum pressure of $200 \mathrm{MPa}$ in order to obtain the pore volume distribution. This method enables the macropore volume (pore diameter larger than $50 \mathrm{~nm}$ according to the IUPAC) and part of the mesopore volume (pore diameter between 2 and $50 \mathrm{~nm}$ ) down to $7.5 \mathrm{~nm}$ to be determined. The variation of the volume intruded with pressure is represented in Figure 2 for the size fraction 1-2 $\mathrm{mm}$ of the TW coal series. This figure was not corrected to account for coal compressibility. Several authors ${ }^{12-15}$ have concluded that mercury penetration in coal at pressures above $10 \mathrm{MPa}$ is actually due to coal compressibility, which they calculate as a constant value. Others have argued that both pore intrusion and compression of coal occur above $10 \mathrm{MPa}^{16,17}$. In this paper a modified method based on that developed by Zwietering and van Krevelen ${ }^{12}$ and Toda and Toyoda ${ }^{13}$ was applied. These authors calculated coal compressibility from the gradient of the first mercury porosimetry intrusion curve above $10 \mathrm{MPa}$. In this work, several consecutive compression cycles were performed on each coal sample until the compression curves were identical. This was normally achieved after three or four compression cycles. It was assumed that at pressures above $10 \mathrm{MPa}$ mercury displacement was due to simultaneous pore-filling and coal compression. Coal pore volume accessible to mercury was obtained by subtracting the last cycle from the first one. In addition, the compressibility of the coal samples was calculated from the slope of the rectilinear region of the last compression cycle. 
A comparison of the results obtained with the above method and those obtained following the method described by other authors ${ }^{12,13}$ is shown in Table 3 for the TW and DH coal series. It appears from the results in Table 3 that mercury uptake at high pressures is presumably due not only to coal compressibility but also to pore penetration. This is supported by the higher pore volume values obtained by the method used in this work in comparison with those obtained by assuming that coal displacement above $10 \mathrm{MPa}$ is only due to coal compression.

Better agreement was found between both methods for the TW coal series than for the DH series. The compressibility values shown in Table 3 were in good agreement with the values obtained by other authors ${ }^{13-15,18}$. The relation between compressibility and coal rank has been studied by other researchers, who found a decrease in compressibility with the increase in coal rank $^{18}$ and the existence of a minimum and a maximum $^{13}$. In this work linear relationships were found between compressibility and ash content for both coal series, as can be observed in Figure 3. No relation was observed between compressibility and particle size, the former being dependant on the ash content of the samples, i.e. the higher the ash content, the lower the compressibility.

\section{Adsorption isotherms in $\mathrm{CO}_{2}$}

Adsorption isotherms of $\mathrm{CO}_{2}$ at $0^{\circ} \mathrm{C}$ from the $1-2 \mathrm{~mm}$ size fraction of TW coal series are presented in Figure 4 and DR plots for the adsorption of $\mathrm{CO}_{2}$ in the 1-2 mm fraction of DH coal series are displayed in Figure 5. Tables 4 and 5 contain the parameters of the Dubinin-Radushkevich equation for the TW and DH coal series, respectively. No special significance should be given to the difference between $S_{D R}$ and $S_{m i}$, as they represent two different ways of calculating the total surface area in $\mathrm{CO}_{2}{ }^{19}$. A comparison between total pore volume accessible to $\mathrm{He}, V_{T}$, and the volume measured by adsorption in $\mathrm{CO}_{2}, W_{0}$, reveals that the volume of micropores is larger than the total pore volume for most of the TW samples, as shown in Figure 6. Exceptions to this behaviour were the samples with high ash content, i.e. the sinks at 2.2 RD at any size fraction and the reject of the $2-4 \mathrm{~mm}$ fraction. This may seem surprising at first but a similar effect has been observed by other authors ${ }^{20-23}$ when comparing the relation between $\left(W_{0^{-}} V_{T}\right)$ and coal rank. In this work positive values of 
$\left(W_{0}-V_{T}\right)$ were found for the density fractions of the same coal (TW), the difference decreasing with relative density, i.e. the ash content of the samples.

Several reasons have been put forward to explain the above phenomena but the most currently accepted one is that suggested by Mahajan ${ }^{22}: \mathrm{CO}_{2}$ gives a higher pore volume because, through imbibition, it is able to penetrate micropores that are inaccessible to helium, which can only enter the pore system by diffusion. The same conclusion can be inferred from the work of Larsen et al. ${ }^{24}$ though they proposed that pores in coals are closed and can only be reached by diffusion through the solid. The TW coal samples used in this work are mostly microporous, as can be deduced by comparing the values of $V_{T}$ and $W_{o}$ in Tables 1 and 4. Accordingly, helium cannot diffuse through the narrow constrictions in the pore network, this resulting in lower total pore volumes than those measured from $\mathrm{CO}_{2}$ adsorption. In consequence, the difference between $V_{T}$ and $W_{o}$ is a measure of the microporous structure of coal, which is not accessible to helium. Different behaviour was displayed by the DH coal samples with higher values of $V_{T}$ than $W_{o}$, due to a higher porosity and a much smaller contribution of the micropores to the total pore volume than in the case of the TW coal series.

Another significant characteristic that can be drawn from the results of the TW series is that the adsorption of $\mathrm{CO}_{2}$ tends to decrease with the increase in the density of separation, i.e. more microporous material is found at lower relative densities. On the other hand, the clean coal, middlings and reject of the DH coal samples present very different textural parameters (Table 5), the total surface area, $\mathrm{S}_{\mathrm{DR}}$, decreasing considerably from a value of $137 \mathrm{~m}^{2} \mathrm{~g}^{-1}$ for the clean coal to $36 \mathrm{~m}^{2} \mathrm{~g}^{-1}$ for the middlings and $18 \mathrm{~m}^{2} \mathrm{~g}^{-1}$ for the reject of the 1-2 $\mathrm{mm}$ size fraction. All this has important implications for coal beneficiation and especially when considering the effect of porosity on float and sink analyses. All the accessible pores in coal (when saturated) will probably be filled with water. Current computer simulation models of density-based processes are based on data derived from float and sink testing. It has been found that errors in predicted yields become important when low ash products are required and this may be due to the effect of porosity. 


\section{CONCLUSIONS}

The textural characterisation of an anthracite and a bituminous coal series has shown that the total pore volume of the bituminous coal series was more than six times greater than that of the anthracite series. In the case of the bituminous coal series studied, there was a linear relationship between coal porosity and ash content, with an increase in porosity for the lower ash material. This might explain why serious errors occur in the prediction of results of low relative density separations in the preparation of low ash coals. A linear relationship between compressibility and the ash content for each coal was found.

\section{ACKNOWLEDGEMENTS}

Work carried out with a financial grant from the European Coal and Steel Community (ECSC Project $7220-$ EA/132).

\section{REFERENCES}

1. Mahajan, O.P. and Walker, P.L. Jr. in Analytical Methods for Coal and Coal Products, Ed. C.Karr Jr., Chapter 4, 125-161, Academic Press, New York, 1978.

2. Buckley, A.N. and Nicol, S.K., CSIRO Investigation Report CET/IR273.

3. Aktas, Z. and Woodburn, E.T., Minerals Engineering, 1994, 7, 1115.

4. Lockhart, N. The Australian Coal Journal, 1992, 37, 11.

5. Abbott, J., Mine \& Quarry, 1996, 25 (1) 30.

6. Rhodes, D., and Miles, N. J., Minerals Engineering, 1991, 4 (3-4), 503.

7. Abbot, J., Mine \& Quarry, 1995, 24 (11), 36.

8. Huang, H., Wang, K., Bodily, D. and Hucka, V.J., Energy \& Fuels, 1995, 9, 20.

9. Dubinin, M.M. in Chemistry and Physics of Carbon, Ed. E.D. Walker, Jr., Vol. 2, 51-120, Dekker, New York, 1966.

10. Garrido, J., Linares-Solano, A., Martín-Martínez, J.M., Molina, M, RodríguezReinoso, F. and Torregrosa, R., Langmuir, 1987, 3, 76.

11. Stoeckli, H.F. and Ballerini, L., Fuel, 1991, 70, 557.

12. Zwietering, P. and van Krevelen, D.W., Fuel, 1954, 33, 331.

13. Toda, Y. and Toyoda, S., Fuel, 1972, 51, 199. 
14. Debelak, K. and Schrodt, J.T., Fuel, 1979, 58, 732.

15. Suuberg, E.M., Deevi, S.C. and Yun, Y., Fuel, 1995, 74 (10), 1522.

16. Friesen, W.I. and Mikula, R.J., Fuel, 1988, 67, 1516.

17. Androutsopoulos, G.P. and Woodburn, E.T., Powder Technology, 1982, 33, 175.

18. Ng, S.H., Fung, D.P. and Kim, S.D., Fuel, 1984, 63, 1564.

19. Parra, J.B., Pis, J.J., de Sousa, J.C., Pajares, J.A. and Bansal, R.C., Carbon, 1996, 34 (6), 783

20. Toda, Y., Fuel, 1972, 51, 108.

21. Walker, P.L. Jr., Philos. Trans. R. Soc. London A300, 65, 1981.

22. Mahajan, O.P., Carbon, 1991, 29 (6), 735.

23. Parkash, S. and Chakrabartty, S.K., Int. J. Coal Geology, 1986, 6, 55.

24. Larsen, J.W., Hall, P. and Wernett, P.C., Energy \& Fuels, 1995, 9, 324. 
Table 1. Textural parameters of the TW coal samples evaluated from displacement of $\mathrm{Hg}$ and $\mathrm{He}$.

\begin{tabular}{|ccccccc|}
\hline Sample & $\begin{array}{c}\text { Size fraction } \\
(\mathrm{mm})\end{array}$ & $\begin{array}{c}\rho_{\mathrm{He}} \\
\left(\mathrm{kg} / \mathrm{m}^{3} \times 10^{-3}\right)\end{array}$ & $\begin{array}{c}\rho_{\mathrm{Hg}} \\
\left(\mathrm{kg} / \mathrm{m}^{3} \times 10^{-3}\right)\end{array}$ & $\begin{array}{c}\varepsilon \\
(\mathrm{vol} \%)\end{array}$ & $\begin{array}{c}\mathrm{V}_{\mathrm{T}} \\
\left(\mathrm{mm}^{3} / \mathrm{g}\right)\end{array}$ & $\begin{array}{c}\text { Ash } \\
(\mathrm{wt} \% \mathrm{db})\end{array}$ \\
\hline Clean coal & & 1.37 & 1.34 & 2.2 & 16 & 4.2 \\
Float 1.4 RD & & 1.36 & 1.34 & 1.5 & 11 & 2.5 \\
$1.4-1.5 \mathrm{RD}$ & & 1.46 & 1.43 & 2.1 & 14 & 11.9 \\
$1.5-1.6 \mathrm{RD}$ & & 1.57 & 1.53 & 2.6 & 17 & 22.5 \\
$1.6-1.7 \mathrm{RD}$ & $2-4$ & 1.69 & 1.64 & 3.0 & 18 & 31.2 \\
$1.7-1.8 \mathrm{RD}$ & & 1.78 & 1.73 & 2.8 & 16 & 39.2 \\
$1.8-2.0 \mathrm{RD}$ & & 1.93 & 1.89 & 2.1 & 11 & 50.0 \\
2.0-2.2 RD & & 2.17 & 2.11 & 2.8 & 13 & 63.7 \\
Sinks 2.2 RD & & 2.59 & 2.47 & 4.6 & 19 & 83.7 \\
Reject & 2.29 & 2.19 & 4.4 & 20 & 68.3 \\
\hline Clean coal & & 1.38 & 1.35 & 2.2 & 16 & 4.2 \\
Float 1.4 RD & & 1.39 & 1.36 & 2.2 & 16 & 2.5 \\
1.4-1.5 RD & $1-2$ & 1.47 & 1.43 & 2.7 & 19 & 12.1 \\
Sinks 2.2 RD & & 2.62 & 2.50 & 4.6 & 18 & 84.0 \\
Reject & & 2.21 & 2.16 & 2.3 & 11 & 63.0 \\
\hline \hline Clean coal & & 1.41 & 1.36 & 3.6 & 26 & 4.3 \\
Float 1.4 RD & & 1.39 & 1.33 & 4.3 & 33 & 2.2 \\
1.4-1.5 RD & $0.5-1.0$ & 1.48 & 1.42 & 4.1 & 29 & 11.4 \\
Sinks 2.2 RD & & 2.64 & 2.52 & 4.6 & 18 & 84.0 \\
Reject & & 2.15 & 2.10 & 2.3 & 11 & 58.7 \\
\hline
\end{tabular}


Table 2. Textural parameters of the DH coal samples evaluated from displacement of $\mathrm{Hg}$ and $\mathrm{He}$.

\begin{tabular}{|ccccccc|}
\hline Sample & $\begin{array}{c}\text { Size fraction } \\
(\mathrm{mm})\end{array}$ & $\begin{array}{c}\rho_{\mathrm{He}} \\
\left(\mathrm{kg} / \mathrm{m}^{3} \times 10^{-3}\right)\end{array}$ & $\begin{array}{c}\rho_{\mathrm{Hg}} \\
\left(\mathrm{kg} / \mathrm{m}^{3} \times 10^{-3}\right)\end{array}$ & $\begin{array}{c}\varepsilon \\
(\mathrm{vol} \%)\end{array}$ & $\begin{array}{c}\mathrm{V}_{\mathrm{T}} \\
\left(\mathrm{mm}^{3} / \mathrm{g}\right)\end{array}$ & $\begin{array}{c}\text { Ash } \\
(\mathrm{wt} \% \mathrm{db})\end{array}$ \\
\hline Clean coal & & 1.36 & 1.16 & 14.7 & 127 & 8.0 \\
Middlings & $1-2$ & 2.18 & 1.99 & 8.7 & 44 & 66.6 \\
Reject & & & & & & \\
\hline \hline Clean coal & & 2.51 & 2.34 & 6.8 & 29 & 77.6 \\
Middlings & $0.5-1$ & 1.34 & 1.11 & 17.2 & 155 & 4.9 \\
Reject & & 1.59 & 1.36 & 14.5 & 106 & 24.5 \\
\hline Clean coal & & 2.39 & 2.21 & 7.5 & 34 & 73.8 \\
Middlings & $0.25-0.5$ & 1.34 & 1.12 & 16.4 & 147 & 4.7 \\
Reject & & 1.38 & 1.17 & 15.2 & 130 & 8.4 \\
\hline
\end{tabular}


Table 3. Comparison between the results obtained by mercury porosimetry following the method of this work and the results obtained applying another method ${ }^{12,13}$ for the TW and DH coal series.

\begin{tabular}{|c|c|c|c|c|c|}
\hline \multirow[t]{2}{*}{ Sample } & \multirow{2}{*}{$\begin{array}{l}\text { Size fraction } \\
(\mathrm{mm})\end{array}$} & \multicolumn{2}{|c|}{ Method of this work } & \multicolumn{2}{|c|}{ Another method $^{12,13}$} \\
\hline & & $\begin{array}{l}\text { Vpores } \\
\left(\mathrm{mm}^{3} / \mathrm{g}\right)\end{array}$ & $\begin{array}{l}\text { Compressibility } \\
\qquad\left(\mathrm{Pa}^{-1} \times 10^{10}\right)\end{array}$ & $\begin{array}{l}\text { Vpores } \\
\left(\mathrm{mm}^{3} / \mathrm{g}\right)\end{array}$ & $\begin{array}{c}\text { Compressibility } \\
\qquad\left(\mathrm{Pa}^{-1} \times 10^{10}\right)\end{array}$ \\
\hline \multicolumn{6}{|c|}{ TW coal series } \\
\hline Clean coal & & 3.2 & 1.06 & 1.6 & 0.96 \\
\hline Float 1.4 RD & & 5.1 & 0.97 & 3.9 & 0.92 \\
\hline 1.6-1.7 RD & $2-4$ & 5.8 & 0.59 & 4.5 & 0.73 \\
\hline 1.7-1.8 RD & & 2.9 & 0.51 & 5.2 & 0.72 \\
\hline 1.8-2.0 RD & & 3.1 & 0.66 & 2.5 & 0.68 \\
\hline Clean coal & & 5.3 & 1.00 & 2.6 & 1.15 \\
\hline Float 1.4 RD & & 4.9 & 1.01 & 3.3 & 1.01 \\
\hline 1.4-1.5 RD & $1-2$ & 5.1 & 1.01 & 3.3 & 1.02 \\
\hline Sinks $2.2 \mathrm{RD}$ & & 4.7 & 0 & 1.9 & 0.34 \\
\hline Reject & & 4.3 & 0.26 & 1.2 & 0.56 \\
\hline Clean coal & & 5.2 & 0.98 & 2.7 & 1.02 \\
\hline Float 1.4 RD & & 5.0 & 1.02 & 1.8 & 1.07 \\
\hline 1.4-1.5 RD & $0.5-1$ & 5.0 & 0.90 & 3.0 & 1.05 \\
\hline Sinks 2.2 RD & & 5.2 & 0.32 & 2.5 & 0.96 \\
\hline Reject & & 3.9 & 0.52 & 2.9 & 0.34 \\
\hline \multicolumn{6}{|c|}{ DH coal series } \\
\hline Clean coal & & 48.1 & 3.18 & 20.5 & 4.21 \\
\hline Middlings & $1-2$ & 17.1 & 1.15 & 7.3 & 1.98 \\
\hline Reject & & 8.3 & 0.92 & 4.3 & 1.37 \\
\hline Clean coal & & 54.8 & 3.31 & 23.6 & 4.37 \\
\hline Middlings & $0.5-1$ & 38.8 & 2.68 & 19.2 & 3.83 \\
\hline Reject & & 10.0 & 0.99 & 6.3 & 1.49 \\
\hline Clean coal & & 48.9 & 3.20 & 23.3 & 4.03 \\
\hline Middlings & $0.25-0.5$ & 44.4 & 2.87 & 20.9 & 3.79 \\
\hline Reject & & 3.1 & 2.21 & 2.0 & 2.95 \\
\hline
\end{tabular}


Table 4. Parameters of Dubinin-Radushkevich equation from $\mathrm{CO}_{2}$ adsorption isotherms of TW coal series.

\begin{tabular}{|lcccccc|}
\hline \multicolumn{1}{|c}{ Sample } & $\begin{array}{c}\text { Size fraction } \\
(\mathrm{mm})\end{array}$ & $\begin{array}{c}\text { Eo } \\
(\mathrm{kJ} / \mathrm{mol})\end{array}$ & $\begin{array}{c}\mathrm{L} \\
(\mathrm{nm})\end{array}$ & $\begin{array}{c}\text { Wo } \\
\left(\mathrm{mm}^{3} / \mathrm{g}\right)\end{array}$ & $\begin{array}{c}\mathrm{S}_{\mathrm{DR}} \\
\left(\mathrm{m}^{2} / \mathrm{g}\right)\end{array}$ & $\begin{array}{c}\mathrm{S}_{\mathrm{mi}} \\
\left(\mathrm{m}^{2} / \mathrm{g}\right)\end{array}$ \\
\hline Clean coal & & 18.2 & 1.58 & 55 & 144 & 70 \\
Float 1.4 RD & & 19.0 & 1.42 & 74 & 193 & 104 \\
1.4-1.5 RD & & 19.1 & 1.41 & 44 & 116 & 63 \\
1.5-1.6 RD & & 18.8 & 1.45 & 47 & 122 & 64 \\
1.6-1.7 RD & $2-4$ & 19.4 & 1.35 & 48 & 125 & 71 \\
1.7-1.8 RD & & 19.5 & 1.33 & 36 & 94 & 54 \\
1.8-2.0 RD & & 19.9 & 1.28 & 31 & 80 & 48 \\
2.0-2.2 RD & & 19.9 & 1.26 & 25 & 65 & 39 \\
Sinks 2.2 RD & & 21.9 & 1.03 & 11 & 28 & 21 \\
Reject & & 20.6 & 1.17 & 16 & 43 & 28 \\
\hline Clean coal & & 18.7 & 1.49 & 63 & 165 & 85 \\
Float 1.4 RD & & 18.1 & 1.60 & 64 & 166 & 79 \\
1.4-1.5 RD & $1-2$ & 19.0 & 1.42 & 57 & 149 & 80 \\
Sinks 2.2 RD & & 21.4 & 1.08 & 10 & 25 & 18 \\
Reject & 20.1 & 1.24 & 17 & 45 & 28 \\
\hline Clean coal & & 19.1 & 1.41 & 78 & 203 & 110 \\
Float 1.4 RD & & 18.6 & 1.51 & 81 & 211 & 107 \\
1.4-1.5 RD & $0.5-1$ & 19.8 & 1.29 & 66 & 174 & 103 \\
Sinks 2.2 RD & & 22.2 & 1.00 & 9 & 23 & 18 \\
Reject & & 20.1 & 1.24 & 27 & 70 & 43 \\
\hline
\end{tabular}


Table 5. Parameters of Dubinin-Radushkevich equation from $\mathrm{CO}_{2}$ adsorption isotherms of the DH coal series.

\begin{tabular}{|lcccccc|}
\hline Sample & $\begin{array}{c}\text { Size fraction } \\
(\mathrm{mm})\end{array}$ & $\begin{array}{c}\text { Eo } \\
(\mathrm{kJ} / \mathrm{mol})\end{array}$ & $\begin{array}{c}\mathrm{L} \\
(\mathrm{nm})\end{array}$ & $\begin{array}{c}\text { Wo } \\
\left(\mathrm{mm}^{3} / \mathrm{g}\right)\end{array}$ & $\begin{array}{c}\mathrm{S}_{\mathrm{DR}} \\
\left(\mathrm{m}^{2} / \mathrm{g}\right)\end{array}$ & $\begin{array}{c}\mathrm{S}_{\mathrm{mi}} \\
\left(\mathrm{m}^{2} / \mathrm{g}\right)\end{array}$ \\
\hline Clean coal & & 21.4 & 1.08 & 52 & 137 & 97 \\
Middlings & $1-2$ & 22.1 & 1.01 & 14 & 36 & 27 \\
Reject & & 22.2 & 1.00 & 7 & 18 & 14 \\
\hline \hline Clean coal & & 21.5 & 1.07 & 54 & 141 & 102 \\
Middlings & $0.5-1$ & 21.9 & 1.03 & 40 & 105 & 78 \\
Reject & & 22.1 & 1.01 & 10 & 26 & 19 \\
\hline Clean coal & & 21.6 & 1.06 & 53 & 140 & 101 \\
Middlings & $0.25-0.5$ & 21.5 & 1.07 & 52 & 136 & 98 \\
Reject & & 21.6 & 1.06 & 32 & 84 & 61 \\
\hline
\end{tabular}




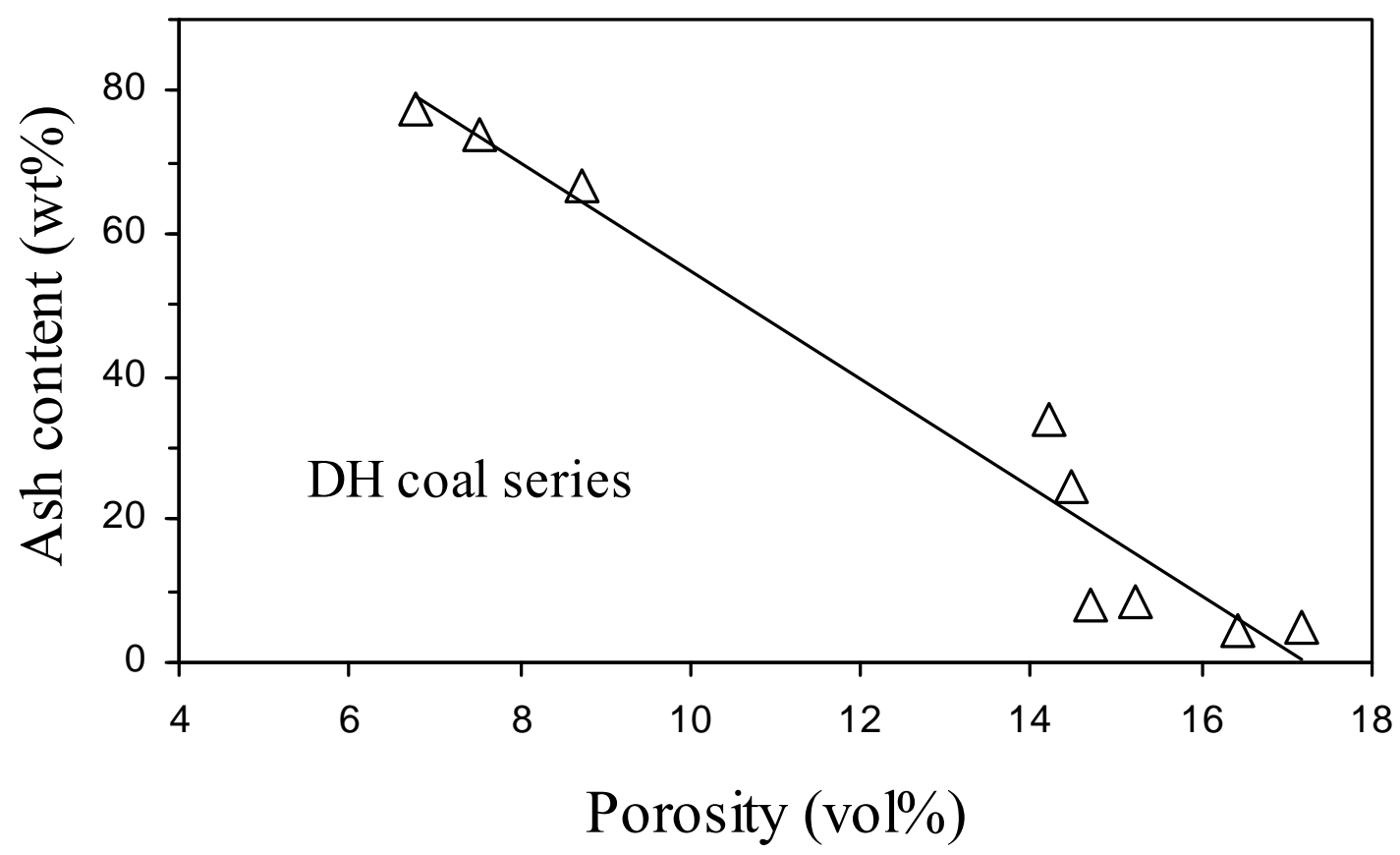

Figure 1. Variation of porosity with the ash content of the DH coal series. 


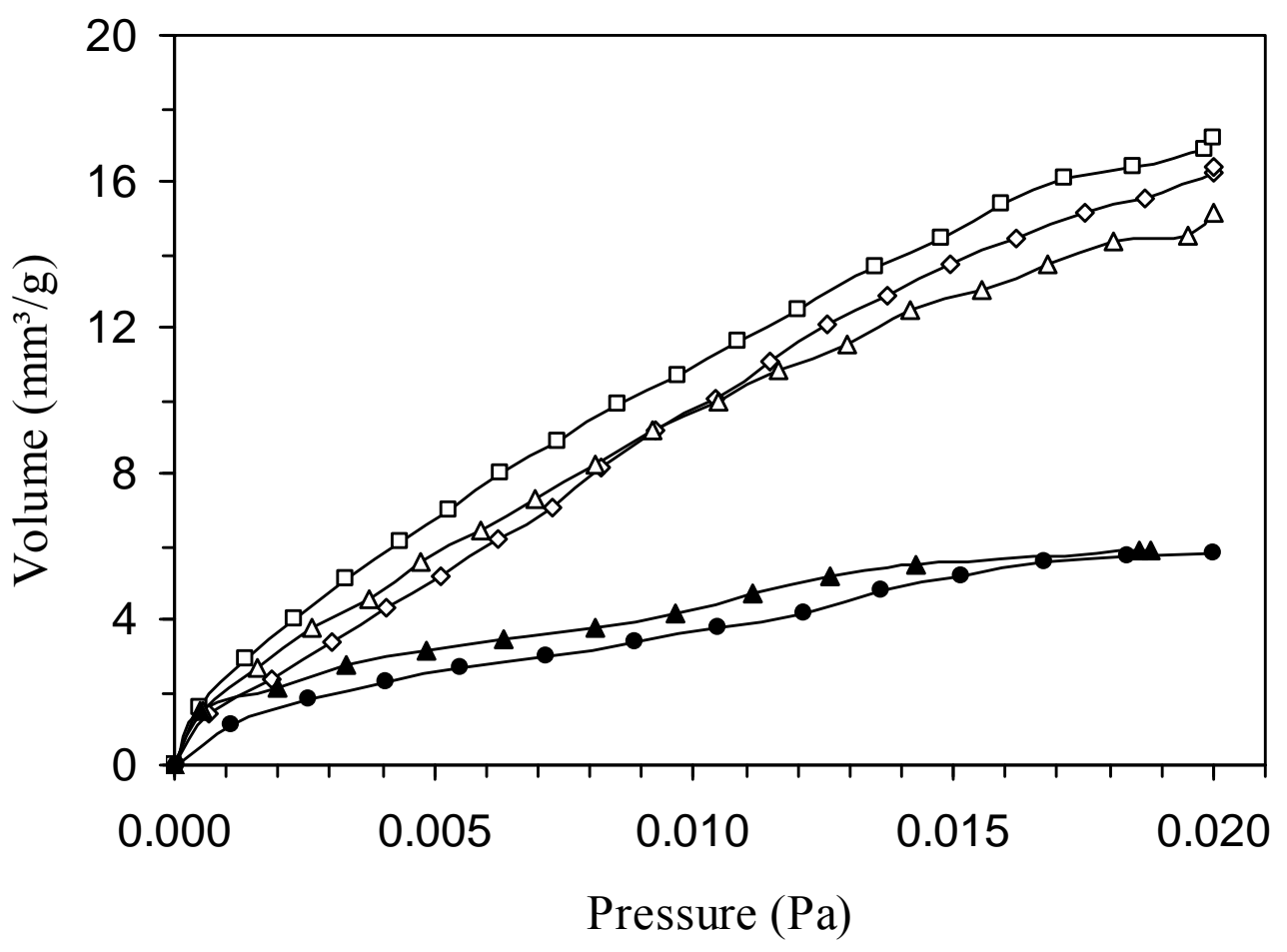

Figure 2. Cumulative pore volume filled with mercury against the applied pressure for the 1-2 mm size fraction of the TW coal series. (Clean coal: $\square$; 1.4 RD: $\diamond ; 1.4-1.5$ RD: $\Delta$; Sinks: $\mathbf{\Lambda}$, Reject: $\bullet$ ). 


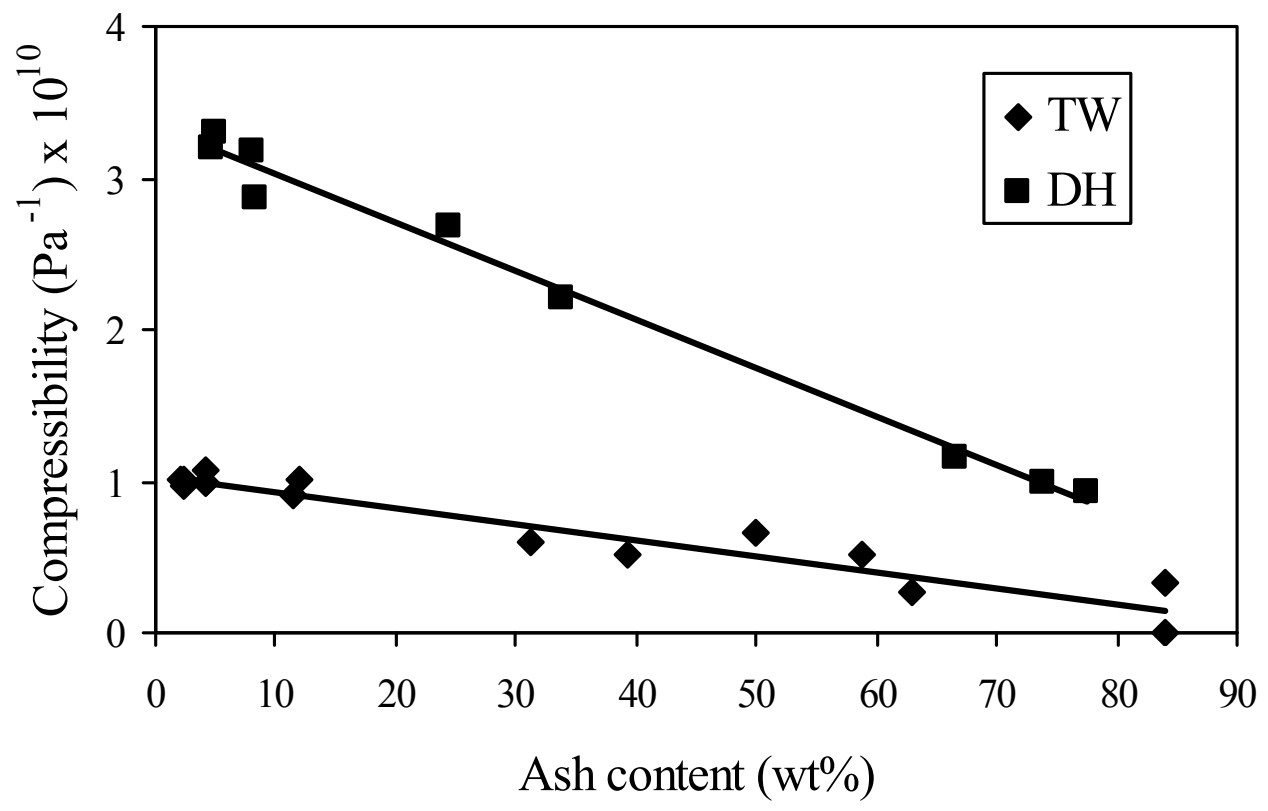

Figure 3. Relation between compressibility and ash content for the TW and DH coal series. 


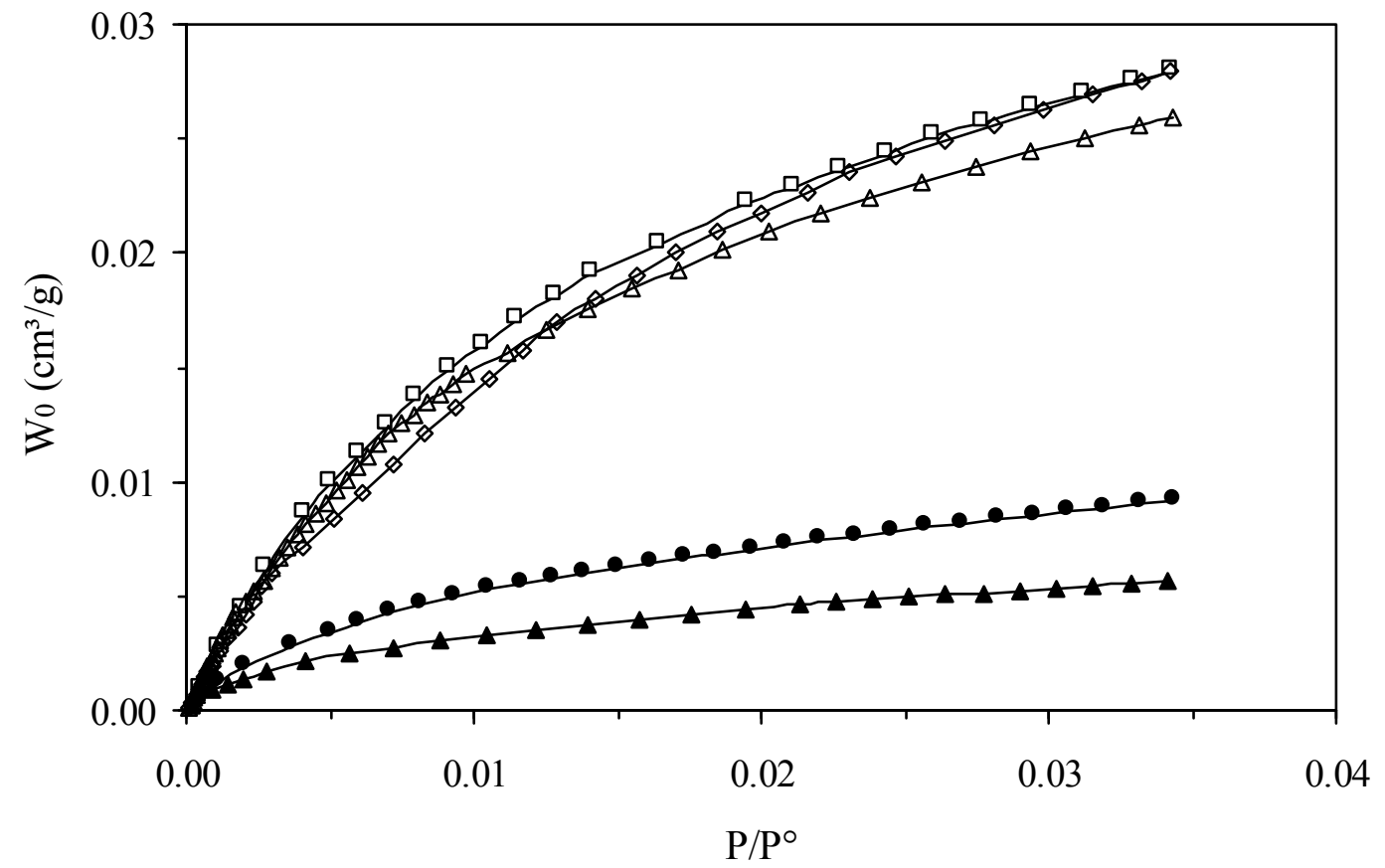

Figure 4. $\mathrm{CO}_{2}$ adsorption isotherms of 1-2 mm size fraction of the TW coal series (Clean coal: $\square$; 1.4 RD: $\diamond$; 1.4-1.5 RD: $\Delta$; Sinks: $\mathbf{\Delta}$, Reject: $\bullet$ ). 


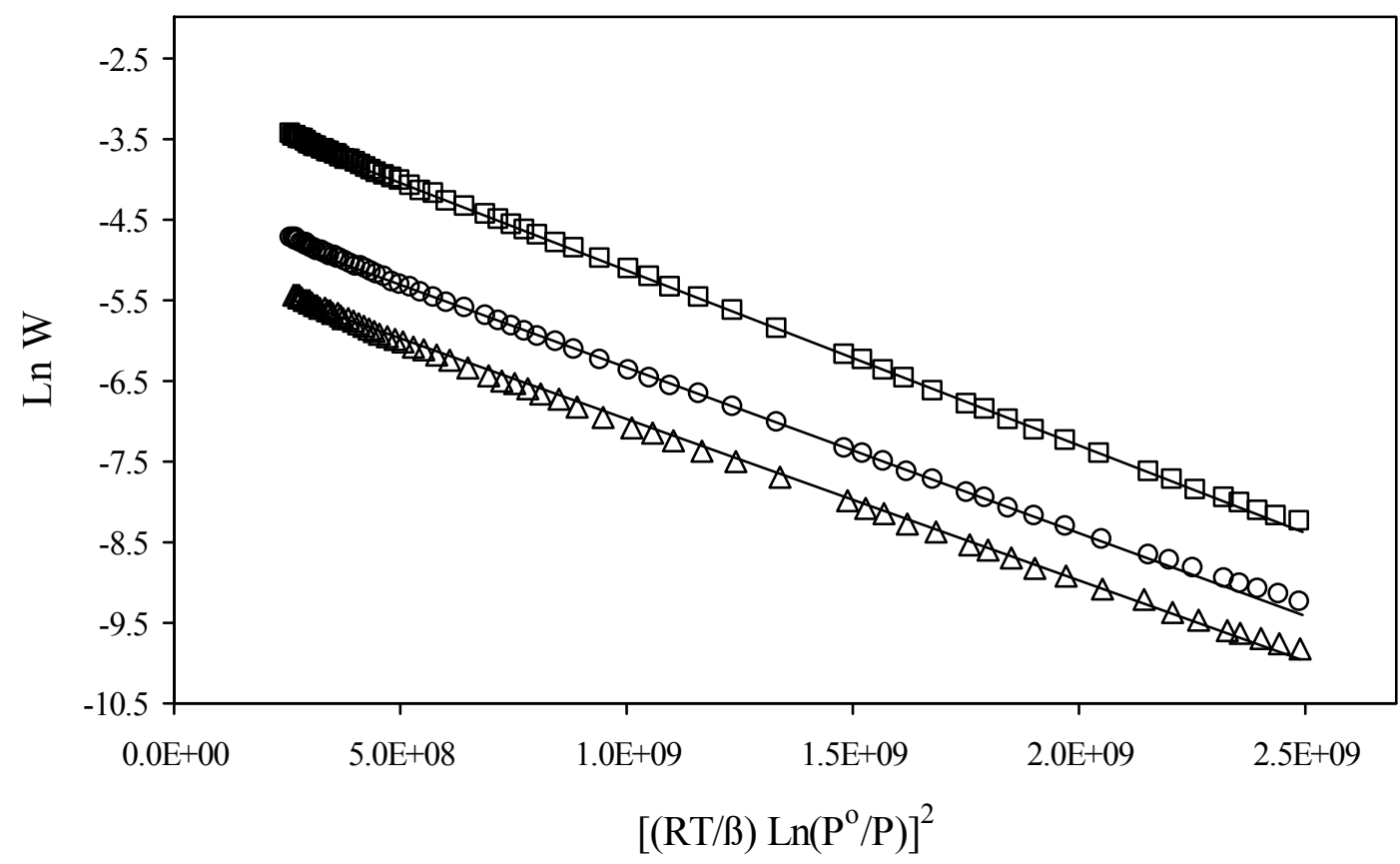

Figure 5. Dubinin-Raduskevich plots for $\mathrm{CO}_{2}$ adsorption isotherms for the 1-2 $\mathrm{mm}$ size fraction of the DH coal series. (Clean coal: $\square$; Middlings: $\odot$; Reject: $\Delta$ ). 


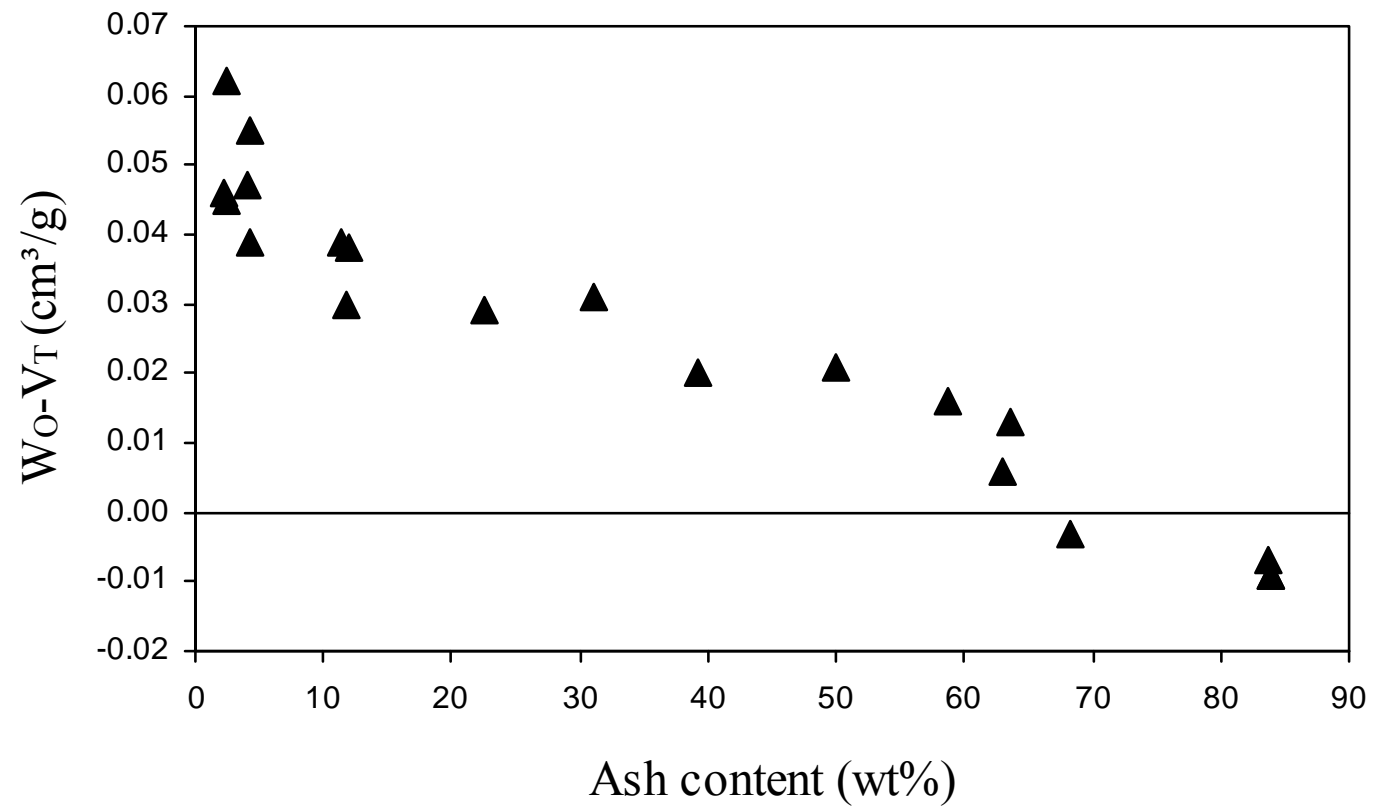

Figure 6. Relation between $\left(\mathrm{W}_{\mathrm{o}}-\mathrm{V}_{\mathrm{T}}\right)$ and ash content of the TW coal samples. 